\title{
Functional Aspects of Elderly Participants of Health Promotion Groups
}

\author{
Vargas DG1, Vargas $\mathrm{JC}^{1}$, Oliveira $\mathrm{MR}^{2 *}$, Foletto Pivetta $\mathrm{HM}^{3}$ and \\ Carvalho De Miranda FA ${ }^{3}$ \\ ${ }^{1}$ Department of Physical Therapy, Federal University of Santa Maria, Brasil \\ ${ }^{2}$ Department of Rehabilitation, Federal University of Santa Maria, Brasil \\ ${ }^{3}$ Department of Physiotherapy and Rehabilitation, Federal University of Santa Maria, \\ Brasil
}

\section{Research article \\ Volume 2 Issue 3}

Received Date: June 24, 2019

Published Date: July 08, 2019

DOI: $10.23880 /$ aphot-16000133

*Corresponding Author: Murilo Rezende Oliveira, Department of Rehabilitation, Federal University of Santa Maria, Avenida General Neto n 477, Bairro Nossa Senhora de Lurdes, Santa Maria-RS, Brasil, Tel: 97105900; Email: murilorezendeoliveira@hotmail.com

\section{Abstract}

Introduction: The elderly population is growing rapidly and within it health systems need to be prepared to provide care and quality of life for this population through health promotion. Therefore, it is necessary that professionals working in these systems, through health promotion groups, know how to reconnect the functionality and level of health of these elderly people to propose preventive treatments and resolutive treatments, avoiding functional deficits and loss of quality of life of the elderly.

Objective: To evaluate the functionality and level of physical activity of elderly participants.

Methods: 29 elderly patients were evaluated. They were assessed using the World Health Organization Disability Assessment Schedule (WHODAS 2.0), Functional Independence Measure (FIM) and the International Physical Activity Questionnaire (IPAQ), which assess functional functionality, functional independence and physical activity level respectively.

Results: The mean age was $70.4 \pm 7.5$ years and the predominant gender was female with $89.95 \%$. Analyzing the functionality, WHODAS showed a mean of $39.9 \pm 8.9$ and the MIF 125.4 \pm 1.2 . Regarding Self-perception of health, $48.3 \%$ of the elderly reported good and at activity level $75 \%$ were active.

Conclusion: It was observed that the evaluated elderly were physically active because they participated in groups of health promotions and the development of actions that have as a presupposition the maintenance of the functionality are necessary to maintain the health of the elderly.

Keywords: Elderly; Functionality; Physical Activity; Health Promotion 


\section{Annals of Physiotherapy \& Occupational Therapy}

Abbreviations: FIM: Functional Independence Measure; UFTM Federal University of the Triangulo Mineiro; MMSE: Mini Mental State Examination; IPAQ: International Physical Activity Questionnaire; BHU: Basic Health Units; SD: standard deviation.

\section{Introduction}

The elderly population in Brazil and in the world is growing rapidly and will be larger than the group of children up to 14 years of age after 2030 [1]. The aging process brings with it bodily, functional and psychological modifications that cause the individual to lose his adaptive capacity to the environment in which he lives, leading to a decline in functional capacity and physical capacity, which can be enhanced by sedentary lifestyle $[2,3]$.

This increase in life expectancy demands new factors of care for public health. As a result, the proposed challenge to public policies regarding the aging of the population includes an increase in the provision of services and benefits [1]. This implies an increase in health promotion actions, thus contributing to a long life with quality [2].

One of the strategies that are being used by professionals in the search for healthy aging is education and health promotion, because health depends on several factors, such as healthy eating, physical activity and good mental state. For this to happen, it is necessary to have public health policies that analyze the health-disease process and the social factors that can interfere in the life of this population [4].

Therefore, it is important that with this study we can understand the health status and the functionality of these elderly people, since the professionals who work in the health promotion centers should develop specific actions aimed at promoting their health [5-7]. From this, the objective of this study was to evaluate the functionality, the level of physical activity and the selfperception of health of elderly participants of health promotion groups.

\section{Methods}

This is an observational, cross-sectional and comparative study carried out in two Basic Health Units (BHU) of a central city in the state of Rio Grande do Sul. Data collection was performed in two health promotion groups of these BHU and in the area. The option for these health units was due to the link between the university and the health service.

The activities in the groups involved kinesiotherapy, health education, ludic activities and cadence of rhythmic movements through various musical rhythms. The meetings were held in an approximate time of one hour, often once a week. The time for the activities was divided into three parts, ten minutes for stretching, ten minutes for education and health lectures, and thirty minutes for dynamic activities.

Included in the study were elderly people enrolled with the BHU, participants for more than 12 months of health promotion groups, of both sexes. All who agreed to participate in the study, signed the Informed Consent Term. Older people with cognitive deficits were considered excluded from the sample. For this purpose, the Mini Mental State Examination (MMSE) was used, in which it is used to verify the general cognitive function and to identify the presence of some undiagnosed cognitive deficit [8]. With this, the elderly were excluded from the study, with scores below 15 (illiterate), less than 22 ( 1 to 11 years of schooling) and less than 27 (schooling over 11 years) [9]. The sample consisted of 29 participants.

The research project was approved by the Committee of Ethics in Research on Human Beings of the responsible Higher Education Institution, under number of the CAAE 63435316.8.0000.5346 and opinion number 2.007.933, following the ethical precepts of researches with human beings, according to Resolution number 466/2012 of the National Health Council.

\section{Data Collection Instruments}

In order to collect the data, questions were firstly asked questions such as: age, sex, schooling, marital status and work activity, in order to delineate the sociodemographic profile of the elderly. The evaluation tools used were the World Health Organization Disability Assessment Schedule (WHODAS 2.0) to delineate the profile and functionality and disability $[10,11]$. The version used to apply the questionnaire was the version with 36 items administered by the interviewer, and the difficulty that the elderly person presented during the last month to perform their tasks was evaluated. This version has the authorization of the World Health Organization granted by granting translation rights and publication for a Portuguese edition for the Federal University of the Triângulo Mineiro - UFTM, [12]. For data analysis the complex punctuation was used, after recommended 
recoding, transforms the results into a metric ranging from 0 to 100 , with 0 indicating no disability and 100 indicating total disability [10].

Another instrument used in the data collection was the Functional Independence Measure (MIF). MIF was used for the evaluation of functional independence through the performance of the individual [13]. The individuals were classified according to the MIF total score: 18 points indicating complete dependence, 19 to 60 points modified dependency (with up to $50 \%$ of tasks); 61 to 103 points modified dependency (aid of up to $25 \%$ of tasks); and 104 to 126 points complete / modified independence [14].

Finally, to evaluate the level of physical activity, the International Physical Activity Questionnaire (IPAQ) was used. This was originally developed with the purpose of estimating the level of habitual practice of physical activity of populations of different countries [15]. The short version of the questionnaire was used, which analyzes the minutes spent on physical activities (moderate, vigorous and walking) in the last seven days. The elderly were classified according to the recommendation of the Coordinating Center of IPAQ in Brazil in very active, active, irregularly active and sedentary.

\section{Statistical Analysis}

Statistical Package for the Social Sciences (SPSS; version 13.0) was used to analyze the data. Data distribution was assessed by the Kolmogorov-Smirnov normality test. Data are presented in frequency, mean and standard deviation (SD). The level of significance of $5 \%$ was considered significant $(\mathrm{p}<0.05)$.

\section{Results}

The sample consisted of 29 elderly people of both sexes. The mean age was $70.4 \pm 7.5$ years. The sociodemographic profile is shown in Table 1.

\begin{tabular}{|c|c|}
\hline Sex & N (\%) \\
\hline Female & $26(89,9)$ \\
\hline Male & $3(10,1)$ \\
\hline \multicolumn{2}{|c|}{ Marital Status } \\
\hline Not married & $1(3,4)$ \\
\hline Married & $11(38,0)$ \\
\hline Separate & $1(3,4)$ \\
\hline Divorced & $8(24,1)$ \\
\hline Widower & $6(31,6)$ \\
\hline Lives together & $2(6,9)$ \\
\hline \multicolumn{2}{|c|}{ Schooling } \\
\hline
\end{tabular}

\begin{tabular}{|c|c|} 
Illiterate & $1(3,4)$ \\
\hline Elementary School & $19(65,5)$ \\
\hline High School & $8(13,8)$ \\
\hline Higher education & $1(3,8)$ \\
\hline \multicolumn{2}{|c|}{ Work } \\
\hline Retired & $19(65,5)$ \\
\hline Homemaker & $8(27,6)$ \\
\hline Pensioner & $1(3,4)$ \\
\hline Autonomous & 0 \\
\hline Unemployed & \\
\hline \multicolumn{2}{|c|}{ MMSE } \\
\hline In average & $2(6,9)$ \\
\hline Below average & $4(13,8)$ \\
\hline Above average & $23(79,3)$ \\
\hline
\end{tabular}

Table 1: Socio-demographic profile of the elderly. MMSE: Mini-mental state examination.

Table 2 shows the averages of the WHODAS domains and the sum of these. This instrument is divided into domains, these being cognition, mobility, self care, relationship, life activities and participation.

\begin{tabular}{|c|c|}
\hline & M \pm SD \\
\hline Cognition & $8,5 \pm 2,2$ \\
\hline Mobility & $6,1 \pm 2,4$ \\
\hline Self Care & $4,2 \pm 0,6$ \\
\hline Relationship & $6,1 \pm 1,8$ \\
\hline Life Activities & $4,7 \pm 1,9$ \\
\hline Participation & $10,2 \pm 3,2$ \\
\hline Total & $39,9 \pm 8,9$ \\
\hline
\end{tabular}

Table 2: WHODAS.

WHODAS: World Health Organization Disability Assessment Schedue.

Table 3 represents a mean score for each of the domains evaluated in the MIF of the evaluated elderly. Being that it is on a scale divided in: personal care, sphincter control, mobility, communication and social knowledge.

\begin{tabular}{|c|c|}
\hline & M \pm SD \\
\hline Personal care & $42 \pm 0$ \\
\hline Sphincter control & $13,8 \pm 0,4$ \\
\hline Mobility & $34,9 \pm 0,4$ \\
\hline Comunication & $13,9 \pm 0,4$ \\
\hline Knowledge social & $20,8 \pm 0,4$ \\
\hline Total & $125,4 \pm 1,2$ \\
\hline
\end{tabular}

Table 3: MIF.

Table 4 represents a mean score for each of the domains evaluated in the IPAQ. Being that this instrument 


\section{Annals of Physiotherapy \& Occupational Therapy}

divides itself into Self-perception of health and activity level.

\begin{tabular}{|c|c|}
\hline & N (\%) \\
\hline \multicolumn{2}{|c|}{ Self-Perception of Health } \\
\hline Great & $3(10,3)$ \\
\hline Very good & $4(13,8)$ \\
\hline Good & $14(48,3)$ \\
\hline Regular & $8(27,6)$ \\
\hline Bad & 0 \\
\hline \multicolumn{2}{|c|}{ Activity Level } \\
\hline Very active & $4(13,8)$ \\
\hline Active & $22(75)$ \\
\hline Irregularly Active A & $2(6,9)$ \\
\hline Irregularly Active B & $1(3,44)$ \\
\hline Inactives & 0 \\
\hline
\end{tabular}

Table 4: Self perception of health and classification of the level of physical activity, according to IPAQ,

\section{Discussion}

The objective of this study was to evaluate the functionality, level of physical activity and self-perception of elderly participants in health promotion groups. According to the results, the elderly in question were physically active and well functioning due to their participation in health promotion groups according to WHODAS, MIF and IPAQ.

In the sociodemographic profile of the elderly participants of the study, a predominantly female population was identified. This issue can be characterized by the feminization of aging, which is due to the fact that women take better care of their health, being less exposed to risk factors and consequently living [16]. Brito and Camargo [17] explain that men seek health services only as curative, since women see prevention as a predominant factor in the care process. This finding contributes to explain the greater number of women participating in the health promotion group.

Another issue to consider is the low level of schooling identified in the sample. This can jeopardize the maintenance of actions taken in the moments of health education, making it difficult to adopt healthy habits and significant changes in lifestyle. Based on these facts, other strategies should be planned to allow access, adherence and permanence of the elderly population to health promotion actions $[3,18]$.

Ribeiro, et al. [19] demonstrated that the elderly who practice physical exercise have greater functional independence than the elderly who did not perform any exercise. It was also found, in this same study, a relation of the MIF with the participation in groups. These findings reveal the importance and necessity of encouraging the participation of these elderly people in groups, since the maintenance of independence helps to keep them active in the community and to reduce the hospitalizations and comorbidities associated with immobility [20].

Regarding self-perception of health, it was observed that the highest percentage was of elderly people who classified health as good. This may be related to the participation in the groups or the attention given by the health teams, since those who received the visit of the Community Health Agents were interviewed. Another issue to consider is that the elderly may be satisfied with the fact that are functionally independent, with no major concerns as to the other issues involved with health as a whole. Considering this context, professionals can set goals, establish priorities for the elderly, both to maintain good health and to improve it, thereby preserving mobility and good health perception [21].

Already the level of physical activity, it was seen that the elderly were active. This finding is related to the participation of the elderly in the health promotion groups, which in addition to keeping the elderly active, performs kinesiotherapy permanently. A study conducted by Benedetti, Mazo, Borges [22] with elderly participants and non-participants of coexistence groups, found a difference between the participation of the elderly in groups and the health condition. The study also showed that the elderly participants in the group had fewer comorbidities, a higher level of physical activity and better health perception than the nonparticipating elderly. According to Toldra, et al. [23], the participation of the elderly in groups provides a broad view of the quality of life and interpersonal learning. As a result, more and more people are investing in public policies aimed at promoting health, especially for the low and middle income population.

In addition to the studies already mentioned, Santos, et al. [24-27] evaluated the improvement of the quality of life in the elderly who participated and did not participate in health promotion groups. It was found that the elderly in the group had higher mean quality of life scores in all Whoqol-Bref domains.

The limitations found in the study are related to the fact that the sample is of convenience of the researchers to the sites, making the results as a regional reference. In addition, it can be inferred that the elderly, although they 


\section{Annals of Physiotherapy \& Occupational Therapy}

participated in the groups for more than 12 months, did not maintain regularity in the sessions of the health promotion groups, making difficult the accuracy of the health interventions of the elderly.

\section{Conclusion}

Thus, it was observed that the evaluated elderly were physically active due to their participation in health promotions groups and because the world population is aging, the development of actions that have as a presumption the maintenance of the functionality has been highly valued since it is known that older people with reduced mobility are more likely to have comorbidities.

It is suggested in future research the comparison of elderly people who participate in health promotion groups and elderly people who do not participate in health promotion groups to quantify the effects of these programs on the health of the elderly.

\section{References}

1. Instituto Brasileiro De Geografia E Estatística (Ibge 2013) Cidade: Rio de Janeiro.

2. Almeida LFF (2015) Community-Based Intervention Project "In Common-Age": contributions to health promotion among the elderly in Vicosa, MG, Brazil. Science \& Collective Healthn. 20(12): 3736-3774.

3. Coelho BS (2014) Comparison of strength and functional capacity between elderly strength training and hydrogymnastics practitioners, and nonpractitioners of physical exercise. Revista Brasileira de Geriatria e Gerontologia17(3): 497-504.

4. Carneiro ACLL (2012) Educacao para a promocao da saude no contexto da atencao primária. Revista Panamericana de Salud Publica, Washington 31(2): 115-120.

5. Paiva ATG (2011) Avaliacao da funcionalidade de familias com idosos 16(1): 22-28.

6. Ferreira PCS, Tavares DMS, Rodrigues RAP (2011) Sociodemographic characteristics, functional status and morbidity among older adults with and without cognitive decline. Acta Paulista de Enfermagem 24(1): 29-35.

7. Pereira DS. Nogueira JAN, Silva CAB (2015) Quality of life and the health status of elderly persons:
8. a population-based study in the central sertao of Ceara. Revista Brasileira de Geriatria e Gerontologia 18(4): 839-908.

9. Altermann CDC (2014) Influence of mental practice and movement observation on motor memory, cognitive function and motor performance in the elderly. Brazilian Journal of Physical Therapy 18(2): 201-209.

10. Folstein MF, Folteins SE, Mchugh PR (1975) "Minimental state" a practical method for grading the cognitive state of patients for the clinician. Journal of Psychiatric Research 12(3): 189-198.

11. Ustun TB (2010) Developing the World Health Organization Disability Assessment Schedule 2.0. Bull World Health Organ 88(11): 815-823.

12. Silveira C (2013) Cross-cultural adaptation of the World Health OrganizationDisability Assessment Schedule (WHODAS 2.0) into Portuguese. Journal of the Brazilian Medical Association 59(3): 234-240.

13. Castro S, Leite SCF (2017) Avaliacao de Saude e Deficiencia Manual do WHO Disability Assessment Schedule Whodas 2.0. Cidade, Minas Gerais. Disponível.

14. Ottenbacher KJ (1996) The reliability of the functional independence measure: a quantitative review.Archives of Physical Medicine and Rehabilitation, 77(12): 1226-1232.

15. Ricci NA, Kubota MT, Cordeiro RC (2005) Concordancia de observacoes sobre a capacidade funcional de idosos em assistencia domiciliar. Revista Saude Pública 39(4): 655-662.

16. Vespasiano BS (2012) The use of the International Physical Activity Questionnaire (IPAQ) as a diagnostic tool for the level of physical fitness: a review in Brazil. Revista Saude Itapetinga 12(32): 49-54.

17. Vieira AA (2015) A Feminizacao da Velhice: em foco as caracteristicas socioeconomicas, pessoais e familiares das idosas e o risco social. Textos \& Contextos Porto Alegre 14(1): 115-131.

18. Brito AMM, Camargo BV (2011) Representacoes sociais, crencas e comportamentos de saude: um estudo comparativo entre homens e mulheres. Temas em Psicologia 19 (1): 283-303. 


\section{Annals of Physiotherapy \& Occupational Therapy}

19. Geib LTC (2012) Social determinants of health in the elderly. Ciencia e saude coletiva, Rio de Janeiro 17(1): 123-133.

20. Ribeiro DKN, Lenardt MH, Michel T, Setoguchi SL, Blanski Grden CR, et al. (2015) Contributory factors for the functional independence of long-lived elders. Revista da Escola de Enfermagem da USP 49(1): 8995.

21. Machado FN, Machado AN, Soares SM (2013) Comparacao entre a capacidade e desempenho: um estudo sobre a funcionalidade de idosos dependentes. Revista Latino-Americana de Enfermagem Ribeirao Preto 21(6): 1321-1329.

22. Silva IT, Pinto Junior EP, Vilela ABA (2014) Self concept of health of elderly living with relatives. Brazilian Journal of Geriatrics and Gerontology 17(2): 275-287.

23. Benedetti TRB, Mazo GZ, Borges L (2012) Health Status And Physical Activity Level Among Older People Engaged And Non-Engaged In Social Groups In Florianopolis 17(8): 2087-2093.
24. Toldra RC (2014) Health and quality of life promotion for old people using bodily practices. Mundo saude 38(2): 159-168.

25. Santos LF, Cavalcante Oliveira LMA, Barbosa MA, Minamisava R, Souza BN, et al. (2017) Participation in a Group as a Resource for the Promotion of Health and the Quality of Life Between Elderly. Revista baiana de enfermagem 31(2): 17868.

26. Centro Coordenador Do Ipaq No Brasil Celafiscs (2011) Cidade Sao Caetano do Sul. Disponivel em.

27. Cogitare Enfermagem Curitiba 16(1): 22-28.

28. Silveira LS (2016) World Health Organization Disability Assessment Schedule (WHODAS 2.0): revisao de literatura dos processos de validacao em grupos distintos e afericao das propriedades psicométricas da versão brasileira para cegos. Dissertacao (Mestrado em Educacao Fisica) Universidade Federal do Triangulo Mineiro, Uberaba. 